\title{
Environmental Problems and Countermeasures of Drinking Water Sources in Northwest China
}

\author{
Li Yan ${ }^{1,2,3,4, *}$ \\ ${ }^{1}$ Institute of Land Engineering and Technology, Shaanxi Provincial Land Engineering Construction \\ Group Co., Ltd., Xi'an 710075, China \\ ${ }^{2}$ Shaanxi Provincial Land Engineering Construction Group Co., Ltd., Xi'an 710075, China \\ ${ }^{3}$ Key Laboratory of Degraded and Unused Land Consolidation Engineering, the Ministry of Natural \\ Resources, Xi'an 710075, China \\ ${ }^{4}$ Shaanxi Provincial Land Consolidation Engineering Technology Research Center, Xi'an 710075, \\ China
}

\begin{abstract}
Through sorting out the current situation of environmental protection of urban centralized drinking water sources in Northwest China, and systematically analyzing the main problems and deficiencies in the process of standardization of centralized drinking water sources. Corresponding countermeasures are proposed from the aspects of system establishment and water source construction, source protection area division, water quality improvement, environmental supervision, etc., which provide references for the next step of water source management, environmental remediation and risk prevention and control.
\end{abstract}

Keywords: northwest China, drinking water sources, environmental problems, countermeasures

\section{Introduction}

Drinking water safety is a necessary guarantee for social and economic development and residents 'stability, and the protection of drinking water sources is of great concern. The northwest region is vast, but droughts and rains are low, and evapotranspiration is strong. In particular, the shortage of water resources and the fragile ecological environment are the biggest factors that restrict the socioeconomic development of the region. Moreover, due to soil erosion, shrinkage of inland rivers and lakes, siltation of reservoirs, large water consumption for agricultural irrigation, and serious water pollution, the construction and protection of drinking water sources in the northwest region are difficult, and high-quality drinking water is even scarce in some areas with scarce groundwater resources ${ }^{[1]}$. In order to implement the "Water Pollution Prevention Law" and achieve the goals of residents' drinking water safety and environmental protection of water sources, the Ministry of Ecology and Environment organized a special action on environmental protection of drinking water sources, and comprehensively investigated the construction, operation,

\footnotetext{
*liyan_hhu@163.com
} 
water quality and environmental improvement of water sources, Inventory of illegal construction in the water source protection area, and issue relevant normative guidelines ${ }^{[2]}$. However, due to the regional natural environment, socio-economic level and water source distribution and other factors, under the new situation, there is still a certain gap between the environmental conditions of drinking water sources in the northwest region and the constantly strict requirements. Therefore, it is necessary to sort out and analyze the standardized construction situation and existing problems of drinking water sources in the northwest region, and provide support for more reasonable water source protection, solving water source supervision problems, and ensuring drinking water health and safety in the future.

\section{Environmental status of drinking water sources}

There are 110 centralized drinking water sources in prefecture-level cities in 6 northwestern provinces (Fig. 1). Among them, groundwater drinking water sources are the largest (75), accounting for $68.18 \%$ of the total water sources. According to the number of drinking water sources: Xinjiang $>$ Shaanxi, Gansu $>$ Qinghai $>$ Ningxia; the number of different types of drinking water sources is: groundwater $>$ reservoir $>$ river type. In recent years, under the National Water Pollution Prevention Action Plan and the special work on environmental protection of drinking water sources, the overall environmental conditions of drinking water sources in various provinces and regions have generally improved, drinking water intake is basically stable, and changes in water quality have not fluctuated much. However, due to urban development and expansion, some drinking water sources are in the central area of the city. The source of drinking water is in an important residential area, office area or commercial area of the city. Water source environmental protection is more difficult, and environmental protection issues in drinking water source protection areas are prominent. In addition, due to the influence of the regional hydrogeological environment, the background value of some water quality indicators is high, and the quality of drinking water for households needs to be further improved.

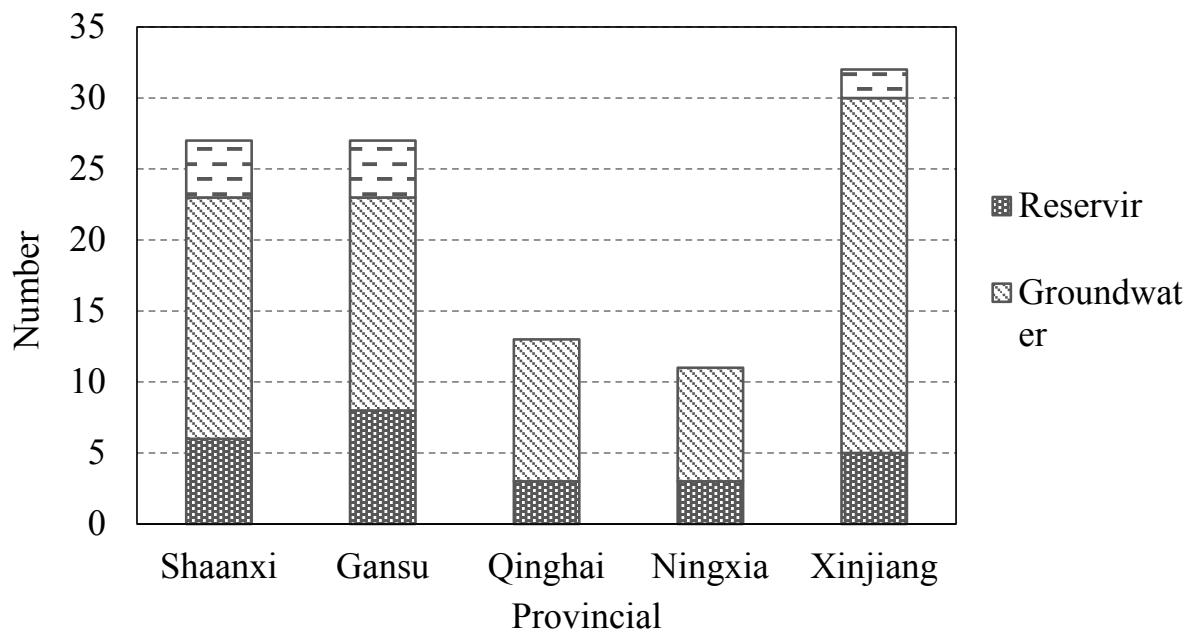

Fig.1 Distribution of drinking water sources in cities in Northwest China

\subsection{Construction of regulation system for drinking water sources}

In order to regulate the construction, protection and management of drinking water sources, 
the " Environmental Protection Laws of PRC" and " The People's Republic of China on Prevention and Control of Water Pollution" make clear requirements for the protection of drinking water sources, issuing guidelines such as the "Technical Guideline for Delineating Source Water Protection Areas" and "The Environmental Protection Technical Requirement for Standardized Construction of Centralized Drinking Water Sources". A series of documents and plans such as the "National Urban Drinking Water Source Environmental Protection Plan" and the "Water Pollution Prevention Action Plan" were issued to make drinking water source environmental protection law-based ${ }^{[3]}$. In order to carry out the protection of drinking water sources according to local conditions, individual provinces and municipalities issued corresponding regulations (methods) for the protection of drinking water sources. For example, in 2012 Qinghai Province promulgated the "Qinghai Province Drinking Water Source Protection Regulations", and in 2019 the Jiuquan Municipal Government issued the "Jiuquan City Drinking Water Source Protection Regulations" to regulate the protection of drinking water sources in its jurisdiction.

For the construction, evaluation and emergency management of drinking water sources, the state has formulated the " Technical Guideline for the Environmental Protection Status Assessment of Centralized Drinking Water Sources" and the "Guidelines for the Preparation of Emergency Preparedness Plans for Environmental Emergency in Centralized Surface Water Drinking Water Sources" guide. In particular, the revision and implementation of the "Groundwater Quality Standards" has further improved the water quality protection and assessment system for groundwater-type drinking water sources.

\subsection{Status of standardized construction of drinking water sources}

The "Water Pollution Prevention Action Plan" states that by 2020, the level of drinking water safety will continue to improve, and the proportion of the quality of centralized drinking water sources in prefecture-level and above cities that meets or exceeds Category III is generally higher than $93 \%$. It is required to ensure the safety of drinking water sources and strengthen the environmental protection of drinking water sources. As of the end of 2019, except for individual drinking water sources in the key cities in the northwest region, the remaining drinking water sources are all divided into protected areas. Signs, isolation protection projects (facilities) have been established in the protected areas, and drinking water source protection the overall situation of the district construction is better ${ }^{[4]}$. Among the drinking water sources in cities in the northwest region, river-type and reservoir-type water sources are mostly located outside the urban area. The overall environment of the drinking water source protection area is relatively good, less affected by human activities, and the original natural environment in the basin is better. However, the environmental conditions of groundwater sources located in urban areas are not optimistic. The intake wells of most water sources are close to large buildings or key urban economic zones, and there are many construction projects in the protected areas. In addition, some cities have a single type of water resources and a relatively small population. There is only a single source of drinking water, and no standby or emergency water sources have been constructed.

\subsection{Supervision and management of drinking water sources}

Based on the national requirements for water quality and management of drinking water sources, drinking water sources need to be regularly monitored for water quality. Among them, the monitoring of water quality of surface drinking water sources carried out basic projects and supplementary projects in accordance with the Environmental Quality Standards for Surface Water (GB3838-2002). The groundwater source water quality 
monitoring and evaluation standards are carried out according to the "Standard for Groundwater Quality" (GB / T14848-2017), and single-factor evaluation is adopted. At present, each drinking water source is monitored monthly (quarterly), but due to the limitation of the monitoring capacity of the water source supervision department, some unconventional indicators in the full analysis of water source water quality must be entrusted to monitor, and the cost is relatively high ${ }^{[5]}$. Especially for Xinjiang's vast and remote water sources, sampling and entrusted testing are difficult under severe weather conditions.

For water source monitoring, almost every water source has been video-monitored, to a large extent, it has achieved dynamic monitoring of water sources around the clock. However, it is still difficult to establish an automatic monitoring station to automatically detect the necessary indicators of water quality for a very large water source with a certain service population and total water intake above a certain scale. In addition, although the water resource responsibility department has established a risk prevention system, emergency plans and expert database, it has implemented a daily water resource management system. However, water source risk identification, prevention and control measures, and emergency response capabilities still need to be improved.

\section{Problems for environmental protection of drinking water sources}

\subsection{The regulation system of drinking water sources is imperfect}

At the national level, more comprehensive regulations and regulations for the construction and protection of drinking water sources have been issued. However, some regulations have not been able to accurately and effectively guide the protection of local drinking water sources, and the special natural environment and social and economic conditions in the northwest region. For example, there are no cage culture activities in the reservoir-type water source area in the northwest region, the watershed area of the reservoir is large, and there are large-scale grazing and tourism projects in the upstream. It is difficult to prohibit grazing by regulating the environment of protected areas. Therefore, on the premise of meeting the regulations at the national level, there is an urgent need to establish and improve a legal system applicable to the protection of drinking water sources in the region.

\subsection{The water quality of drinking water sources is poor}

Drinking water sources are the basic resources for social and economic development and people's production and life. The protection of water sources has always received much attention. The overall quality of drinking water sources in Northwest China is relatively good, and the quality of surface water sources is relatively better than that of groundwater sources. Most of the river-type and reservoir-type water sources fail to meet the water quality standards, which is caused by excessive conventional nutrients such as total phosphorus and total nitrogen. The indicators of groundwater quality exceeding the standard include total hardness, total dissolved solids, sulfate, chloride, fluoride and so on. Excessive water quality is not only due to the influence of non-point source pollution of agricultural production, grazing, tourism and living, but also due to the high natural background value of indicators in the region where the water is located. Moreover, due to the lack of regional water resources, the small choice of alternative water sources, and the high cost of cross-regional remote water transfer, it is difficult to develop new water sources that meet the standards at this stage. 


\subsection{Imperfect construction of water source protection area}

Some groundwater drinking water sources located in urban built-up areas in the northwestern region have long running hours, wells and water supply facilities are seriously aging, water resources are depleted, early drinking water source protection mechanisms are imperfect, and other historical legacy issues. The well is close to large buildings or key urban economic zones, and there are many construction projects in the protected area. In addition, the number of wells for individual groundwater sources is large and distributed, and they locate in urban built-up areas. At present, it is not possible to carry out the division of protected areas. The construction of protected areas and environmental remediation are even more difficult.

\subsection{Inadequate capacity building for water source environmental supervision}

The overall construction of environmental monitoring capacity in the northwest region is lagging. The water quality monitoring of drinking water sources is mainly undertaken by provincial and municipal environmental protection departments. The municipal-level environmental protection monitoring departments have incomplete monitoring equipment configuration and lack of professional and technical personnel, and can only complete the monitoring of basic indicators of the departments. Most unconventional indicators mainly rely on provincial-level monitoring departments and third-party monitoring agencies in the market, and the higher monitoring costs have great financial pressure on grassroots environmental protection departments.

\section{Environmental protection countermeasures for drinking water sources}

(1) Accelerate and improve the legal system for the protection of drinking water sources

Regarding the construction of drinking water source protection laws and regulations, the people's governments of various provinces and autonomous regions will take the lead, based on the existing laws and regulations on the construction and management of drinking water sources in the country and jurisdiction. Combine the natural environmental conditions, socio-economic conditions and the characteristics of drinking water sources in the area under its jurisdiction. Formulate system measures for environmental protection and management of drinking water sources in their jurisdictions according to local conditions.

(2) Implement drinking water source protection area system

Governments at all levels strictly implement the drinking water source protection zone system in accordance with the requirements of the National Water Pollution Prevention Law and the Environmental Protection Law. For drinking water sources that have not yet been divided into protected areas, demonstrate the necessity, feasibility and cost of continued operation of the water source, and study the division of water source protection areas. It is indeed unconditional and effective to divide the protection zone to effectively protect the water source. It is recommended that the government organize to develop new alternative water sources, divide the protection zone, and complete the construction and renovation of the protection zone. However, during the construction of alternative water sources, it must be ensured that the quantity and quality of existing water sources do not continue to deteriorate, affecting the drinking water safety of residents.

(3) Management of water quality target for drinking water sources

The "Water Pollution Prevention Action Plan" clearly proposes to supervise drinking water safety from the source to the faucet. People's governments at all levels and water supply units shall regularly monitor, test and evaluate the drinking water safety status of 
drinking water sources, water supply plant effluents and user faucet water quality in their administrative areas. For water sources whose water quality does not meet the standards, a near-term and long-term water quality compliance plan should be formulated. If the water source quality compliance is indeed unconditionally achieved, the process of the water supply plant should be started to ensure that the water quality entering the water supply network meets the drinking water hygiene requirements and ensures the safety of residents 'drinking water.

(4) Further strengthen the capacity building of water source supervision

Starting from the government, multiple departments coordinated and strengthened environmental monitoring capacity building. Starting from the training of professional and technical personnel and the configuration of precision monitoring equipment, from the provincial level to the municipal level, strengthening monitoring methods, testing capabilities and testing efficiency to ensure full coverage of drinking water source water quality monitoring, cooperating with many places to carry out regular water quality analysis and tracking The water quality of the water source is safe.

\section{Conclusion}

Drinking water safety concerns the immediate interests of the people. Nowadays, the drinking water sources in the northwest region are mainly groundwater, and the overall environmental protection and supervision of water sources are stable and improving. Faced with difficulties in localization of drinking water source protection laws and regulations, insufficient basis for environmental standardization of water sources, difficulties in resolving historical problems, regional natural environmental conditions restricting water source construction, and insufficient water source supervision capabilities, the article proposes to improve the legal system Implement measures such as the protected area system, water source quality improvement management, and strengthening environmental monitoring capabilities to provide references for the construction and protection of regional drinking water sources.

\section{References}

1. Xie Q, Fu Q, Chang S, et al. Standardized management mechanism of urban drinking water source and its driving effect on water quality improvement [J]. Journal of Northwest University (Natural Science Edition), 2016, 50(1):68-74.

2. Li Y. Safety guarantee of rural drinking water sources and prevention of water Environment pollution [J]. Resource Conservation and Environmental Protection, 2020, (01):30.

3. Fu Q. Protection of drinking water sources in Beijing, Tianjin and Hebei Province [J]. Environmental Protection, 2016, 44(16):43-45.

4. Fu Q, Zhao S Y, Zheng Y. Environmental problems and countermeasures of the town drinking water resources in China [J]. Environment and Sustainable Development, 2014, 39(6):58-60.

5. Li D X, Wang J H, Zhang X, et al. Discussion on Ecological Restoration Technology for Construction Sites of Drinking Water Sources-Taking Mobaxia Reservoir Water Source Project in Chengxian County, Gansu Province [J]. Soil and Water Conservation in China, 2020, (01):21-25. 